\title{
The carbon reactions of photosynthesis: role of lectins and glycoregulation
}

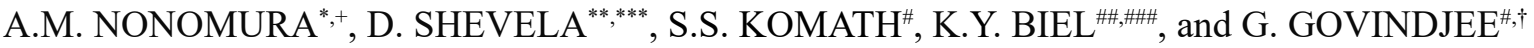 \\ Carbon Reactions of Photosynthesis Sector, BRANDT iHammer, Powell, Ohio, USA* \\ Department of Chemistry, Chemical Biological Centre, Umeå University, Umeå, Sweden ** \\ ShevelaDesign AB, Umeå, Sweden ${ }^{* * *}$ \\ School of Life Sciences, Jawaharlal Nehru University, New Delhi, India ${ }^{\#}$ \\ Institute of Basic Biological Problems, Russian Academy of Sciences, Pushchino, Russia \\ Biosphere Systems International Foundation, Tucson, Arizona, USA ${ }^{\# \#}$ \\ Department of Plant Biology, Department of Biochemistry, and Center of Biophysics \& Quantitative Biology, \\ University of Illinois at Urbana-Champaign, Urbana, Illinois, USA ${ }^{\dagger}$
}

\begin{abstract}
Modulation of glycoregulation in agriculture is reviewed here with emphasis on the elucidation of previously unknown pathways involving vacuolar lectins as well as a bypass of lectins that direct free sugars toward productivity. The reversible binding sequences of the endogenous lectin cycle are compared to an induced lectin bypass, as follows. (1) In the cycle, carbohydrate ligands, with similar binding specificities that compete for binding sites on lectins, are involved in the natural cycle of sugar exchanges. (2) For the bypass, tightly bound ligands that occupy lectins prevent free sugars from binding, making them available for productivity. This bypass is induced by methyl- $\alpha$-D-mannopyranoside, a biochemical plant growth regulator for photosynthesis. Integration of this novel technology, with structural elements crucial for ligand binding by the lectins and with nitrogen assimilation, provides the basis for successful modulation of glycoregulation in crops for enhancement of quality and quantity.
\end{abstract}

Keywords: agglutinin; Benson-Bassham-Calvin cycle; concanavalin A; dark reactions; mannose-binding specificity; $\alpha$-D-mannoside.

\section{Introduction}

We present our perspective on the carbon reactions of photosynthesis that includes key investigations from a series that had been initiated by Melvin Calvin and Andrew A. Benson in 'The Path of Carbon in Photosynthesis' (Calvin and Benson 1948; for historical reviews, see Benson 2002, Bassham 2003, Sharkey 2019, Govindjee 2020). Later investigations published in this series, starting with Nonomura and Benson (1992a) and ending with Nonomura et al. (2017), led to the recognition of a major role for lectins in plants (Benson and Nonomura 1992, Nonomura and Benson 1992b, 2012, 2013, 2014; Benson et al. 2009, Biel et al. 2010, Nonomura et al. 2011, 2012). This laid the groundwork for the development of methods for inducing the modulation of glycoregulation by lectins that affects the carbon reactions of photosynthesis (for the carbon reactions, formerly known as the dark reactions, see Buchanan 2016) involving the action of a novel biochemical class of plant growth regulators (Biel and Fomina 2015, Nonomura et al. 2018a, 2020) on the path of carbohydrates, such as glucose $(\mathrm{Glc}$; Fig. $1 A)$ and methyl- $\beta$-D-glycopyranoside $(\beta \mathrm{MeG}$; Fig. $1 B)$.

Methyl- $\alpha$-D-mannopyranoside ( $\alpha$ MeM; Fig. $1 C$ ) is the active ingredient in the commercial plant growth regulator, BRANDT GlucoPro, that was recently developed for field treatment of crops (see section 'Label information'). It induces free sugars to bypass the plant lectin cycle (for a background on this metabolic pathway, see Nonomura et al. 2017, 2018a, 2020; Govindjee et al. 2020).

We provide below an introduction to the function of lectins in the carbon reactions of photosynthesis, and then we describe the bypass in plants, with diagrams of metabolic pathways that compare it to the endogenous lectin cycle.

\section{The role of lectins in plants}

Lectins are proteins that possess at least one noncatalytic domain that is capable of reversibly binding free sugars

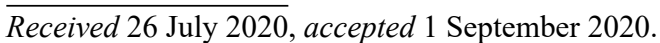

${ }^{+}$Corresponding author; e-mail: Art.N@BRANDTiHammer.Co

Abbreviations: CBA - carbohydrate-binding agent; ConA - concanavalin A; CRD - carbohydrate recognition domain; Glc - $\beta$-D-glucose; Glc/Man - glucose/mannose; IAA - indoleacetic acid; $\alpha \mathrm{MeM}$ - methyl- $\alpha-\mathrm{D}$-mannopyranoside; $\beta \mathrm{MeG}$ - methyl- $\beta$-D-glucopyranoside. Acknowledgments: We thank Michael S. McBride and David H. Gribler of BRANDT iHammer for reviewing this manuscript before its publication. We greatly appreciate Chandra L. Roberts for executive oversight of BRANDT GlucoPro® Plant Growth Regulator. 
A<smiles>OCC1OC(O)C(O)C(O)C1O</smiles>
$B$<smiles>COC1OC(CO)C(O)C(O)C1O</smiles>

C<smiles>COC1OC(CO)C(O)C1O</smiles>

$D$

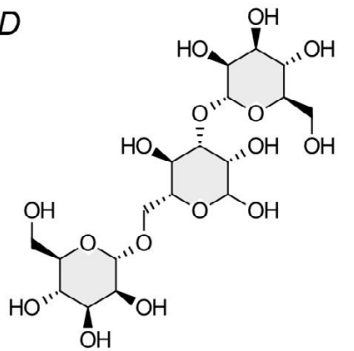

Fig. 1. Chemical structures of $\beta$-D-glucose (Glc) $(A)$, methyl- $\beta$ D-glucopyranoside $(\beta \mathrm{MeG})(B)$, methyl- $\alpha$-D-mannopyranoside $(\alpha \mathrm{MeM})(C)$, and trimannopyranoside $(D)$.

or glycans (Sharon and Lis 2007). The nomenclature and classification of lectins have evolved with the field and multiple methods of classification exist for these proteins (Komath et al. 2006). Based on sequence conservation amongst their carbohydrate recognition domains alone, lectins are organized into twelve evolutionarily conserved families (Van Damme et al. 2008).

The ubiquitous presence of different types of lectins across the plant kingdom is matched by their enormous variety of linkable carbohydrates (see, e.g., Van Damme et al. 1998). Lectins in plants are defined by their specificities for recognition of various saccharides, primarily Glc, mannose, galactose, fucose, and their $\mathrm{N}$-linked derivatives. Lectins account for as much as a tenth of the total protein dry mass in seeds, particularly in beans (Sharon and Lis 2007). Further, their localization varies according to the structures, tissues, and organelles of a given species, depending on the specific requirements and properties of the plants. For example, some nucleocytoplasmic lectins provide protective mechanisms in plants (Lannoo and Van Damme 2014) and some appear to be involved in stress signaling (Lambin et al. 2020). Similarly, some legume lectins provide the receptors required for Rhizobium bacteria to bind to root hairs and to produce nodules (Laus et al. 2006). Yet, other lectins may have a role in developmental regulation and immobilization of sugars (Lannoo and Van Damme 2010). However, in this minireview, we focus on the structure and function of the lectins present in vacuoles of cells in roots, shoots, and seeds of flowering plants (Nonomura et al. 2017).

Thylakoid membranes from several plants have been demonstrated to possess lectins and, in at least one case, they have been shown to interact with Rubisco in a galacturonic acid-dependent manner (Schröder and Petit 1992, Hincha et al. 1993, Aleksidze et al. 2002). More recently, it was shown that some lectins in stroma provide ligands to Rubisco (Kovalchuk et al. 2012). The significance of these observations became apparent when Nonomura and
Benson (2014) recognized that vacuolar lectins function in photosynthesis. As many of the well-characterized plant lectins are secretory proteins that tend to accumulate in the vacuoles, perhaps, one of the most spectacular roles of vacuolar lectins is in the carbon reactions of photosynthesis (Nonomura and Benson 2014, Nonomura et al. 2017, Govindjee et al. 2020) since regulation of this pathway has widespread applications in agriculture.

Historically, the first step towards the elucidation of this role of lectin was taken when ${ }^{13} \mathrm{C}$-labeled $\beta \mathrm{MeG}$ was identified, by in vitro ${ }^{13} \mathrm{C}$-NMR assays, to accumulate in sycamore cells treated with ${ }^{13} \mathrm{C}$-methanol (Gout et al. 2000). Significantly, Benson et al. (2009) established that the treatment of plants with methyl glucopyranosides $(\mathrm{MeG})$ enhanced growth. Soon thereafter, Biel et al. (2010) demonstrated that most of the ${ }^{14} \mathrm{C}-\beta \mathrm{MeG}$ given to Beta vulgaris remained stable within the root cells and that there was no further catabolism after exogenous $\beta \mathrm{MeG}$ was linked to an amine. This was a conundrum. If $\beta \mathrm{MeG}$ had been stored in a protein, then how could it have promoted growth?

Noting the high content of lectins in seeds, Nonomura and Benson (2013) (1) devised a rapid bioassay as a method to further study this phenomenon that was based on monitoring the germination of radish seeds; and, (2) compared responses of seedlings of various species of Brassicaceae to $\alpha$ - and $\beta$-anomers of lectin substrates. From these experiments, Nonomura and Benson (2013) concluded that $\alpha$-D-glycopyranosides have higher potencies for enhancing seedling development than $\beta$-D-glycopyranosides. Furthermore, $\alpha$-D-mannopyranosides, too, produced rapid growth enhancement in the presence of nutrients and this was found to be not only in radish but also in other $\mathrm{C}_{3}$ plants, as well as in $\mathrm{CAM}$ and $\mathrm{C}_{4}$ plants, clearly suggesting that the function of lectins in this process is widespread and probably ubiquitous. In addition, the following order of effective dose response in the treatment of plants was observed: $\alpha$-D-trimannopyranoside $(0.01 \mathrm{mM})>\alpha \mathrm{MeM}(0.03 \mathrm{mM})>\beta \mathrm{MeG}(309 \mathrm{mM})>\mathrm{Glc}$ $(>309 \mathrm{mM})$ (Nonomura et al. 2012, Nonomura and Benson 2013, 2014). In another observation, the requirement of $\mathrm{Ca}^{2+}$ and $\mathrm{Mn}^{2+}$ for hastening the germination process in the presence of substrates was shown (Nonomura and Benson 2014).

Several plant lectins that bind to glucose/mannose (Glc/Man) already have been well-characterized and molecular details of their carbohydrate recognition, as well as ligand specificities are now available (see, for example, Barre et al. 2001, 2019). These include many legume and bulb lectins, such as concanavalin A (ConA), Pisum sativum lectin (PSA), Lathyrus ochrus I lectin (LOL-I), and snowdrop (Galanthus nivalis) lectin (GNA). Several amongst them, but not all, are known to require $\mathrm{Ca}^{2+}$ and $\mathrm{Mn}^{2+}$ in their carbohydrate recognition domains (CRDs). Since they are generally multi-subunit proteins, with the CRD of each subunit possessing extended binding sites, oligosaccharides and multivalent ligands are the preferred choices over simple monosaccharides (Schwarz et al. 1993, Naismith and Field 1996, Smeets et al. 1997, 
Loris et al. 1998, Dam and Brewer 2007). For example, ConA is a Glc/Man binding homotetrameric lectin with greater specificity for trimannosides over simpler sugars (Naismith et al. 1994, Naismith and Field 1996). Each of its monomers possesses a single CRD with tightly bound $\mathrm{Ca}^{2+}$ and $\mathrm{Mn}^{2+}$ ions that participate in ligand binding.

Extrapolating from the above information, it became apparent that the $\mathrm{Ca}^{2+}$ and $\mathrm{Mn}^{2+}$ dependent Glc/Manbinding lectins were involved in the stimulation of plant growth that Nonomura and Benson (2014) had observed. These key experimental observations showing the correspondence of plant responses to lectins are summarized in Table 1.

As implied above, multi-subunit lectins bind oligosaccharides better than monosaccharides. Consistent with this, Nonomura and Benson (2014) observed the high efficacy of trimannopyranoside $(10 \mu \mathrm{M}$; Fig. $1 D)$ in stimulating growth. In contrast to this, blends of $\alpha$ - and $\beta$-anomers in syrups of MeG (309 mM) were among the least potent (Benson et al. 2009). In general, in these investigations, oligosaccharides exhibited the highest potencies in all cases. From these trends of binding specificities, a natural cycle of chemical competition for storage and release of sugars from lectins was recognized (Nonomura and Benson 2014). When presented with two sugars of comparable affinities, a lectin would bind to the one that is present at a higher concentration. Thus, by modulating concentrations of the alternate sugars, the bound ligand may be exchanged with the competing ligand. In contrast, when a lectin is exposed to a ligand with a very strong binding affinity it would bind tightly, allowing little chance for further exchange except at extremely high concentrations of a competing ligand.

The chloroplast is well known to be a site for regulation of photosynthesis by inorganic carbon (see, for example, Shevela et al. 2012, 2020) and a site for regulation in the path of organic carbon (Armbruster and Strand 2020). Recently, it became clear that the vacuole may be a hub for the modulation of glycoregulation since the Glc/Man-binding lectins are located there (Govindjee et al.
2020, Nonomura et al. 2017). For educational purposes, we describe the endogenous plant lectin cycle as would operate in the plant before treatment with $\alpha \mathrm{MeM}$, and then we show how the plant lectin bypass is induced by the treatment of crops with such a ligand of strong binding affinity.

\section{Endogenous lectin cycle in plants}

The natural lectin cycle begins with carbon fixation (see Fig. 2). Atmospheric $\mathrm{CO}_{2}$, as well as $\mathrm{CO}_{2}$ from other plant tissues already present in the vicinity, enter cells and reach the stroma, where the photosynthetic carbon reduction cycle takes place (for historical reviews, see Benson 2002, Bassham 2003, Fomina and Biel 2016, Sharkey 2019; and for a general background of photosynthesis, see Shevela et al. 2018). Some of the products of the photosynthetic carbon reduction cycle, such as sugars, are transported from the chloroplasts into the vacuoles of plant cells, where they bind one or more specific lectins that are involved in the carbon reactions of photosynthesis (carbon reaction lectins). We represent the sugar products of carbon reduction by Glc. The ligands, Glc and $\beta \mathrm{MeG}$, have comparable affinities for binding lectins. Thus, as Glc is consumed by respiration, its concentration decreases to a point where endogenous $\beta \mathrm{MeG}$ is able to displace bound Glc from these lectins. Thereafter, as the concentration of Glc increases in the vacuole, due to fresh supplies from the photosynthetic carbon reduction cycle, Glc successfully outcompetes $\beta \mathrm{MeG}$ to, once again, bind lectins. This completes the endogenous cycle. As Glc level drops and it becomes depleted, $\beta \mathrm{MeG}$, again, exchanges with Glc to occupy the CRD of the lectins, and the cycle repeats. Fig. 2 shows the endogenous lectin cycle in plant cells (as modified from Fig. 1S, supplement).

\section{Induced plant lectin bypass}

Treatment of plants with highly competitive ligands of the lectins, such as $\alpha \mathrm{MeM}$, induces changes in the

Table 1. Characterization of lectins corresponding to experimental results.

\begin{tabular}{|c|c|}
\hline Lectin property & Reference \\
\hline$\beta \mathrm{MeG}$, ligand & Benson et al. (2009) \\
\hline$\beta \mathrm{MeG}$-linked protein & Biel et al. (2010) \\
\hline$\beta$ MeG unmodified, not catabolized & Aubert et al. (2004), Biel at al. (2010) \\
\hline Kinetin riboside, ligand & Nonomura et al. (2011) \\
\hline $\begin{array}{l}\alpha \text {-anomer specificity greater than } \beta \text {-anomer } \\
\text { Mannose specificity greater than glucose }\end{array}$ & Nonomura et al. (2013) \\
\hline $\begin{array}{l}\alpha \mathrm{MeM} \text {, specificity } \\
\text { Trimannopyranoside, high specificity } \\
\text { Structural } \mathrm{Ca}^{2+} \text { and } \mathrm{Mn}^{2+}\end{array}$ & Nonomura and Benson (2014) \\
\hline Modulation of glycoregulation & Nonomura et al. (2017) \\
\hline$\alpha \mathrm{MeM}$-induced sugars & Nonomura et al. (2018b) \\
\hline
\end{tabular}




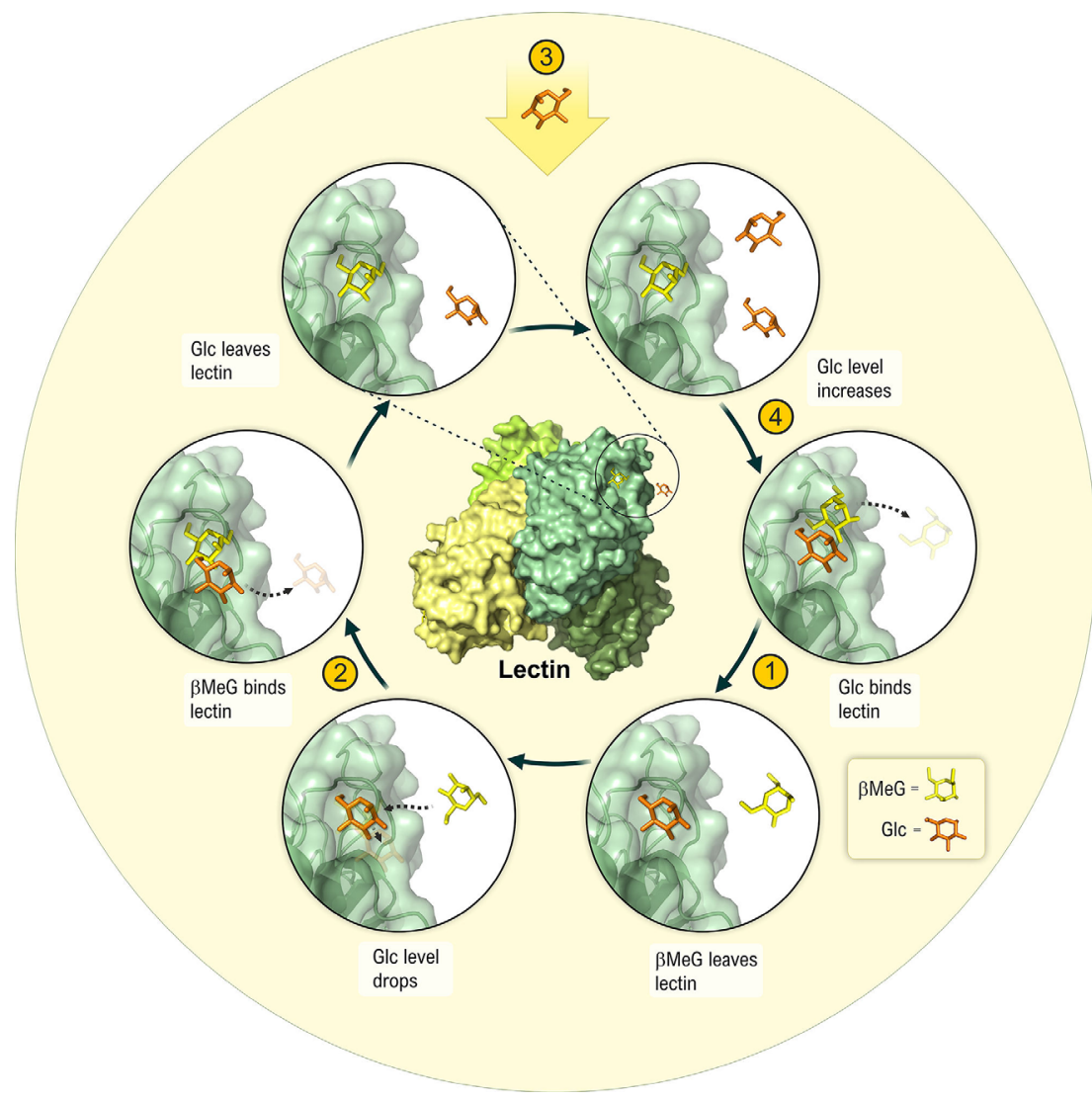

Fig. 2. Diagram of the endogenous lectin cycle in plants. It begins with $\mathrm{CO}_{2}$ entering cells, leading to the photosynthetic carbon reduction cycle. Products are transported from chloroplasts into vacuoles where some of the free sugars, represented by glucose (Glc), bind carbon reaction lectins (1). When Glc concentration drops, endogenous methyl- $\beta$-D-glucopyranoside $(\beta \mathrm{MeG})$ binds lectins. Glc leaves lectin (2) Thereafter, fresh supplies of Glc from the photosynthetic carbon reduction cycle (3) increase the concentration of Glc in the vacuole and it successfully outcompetes $\beta \mathrm{MeG}$ to, once again, bind lectins (4). This completes the endogenous cycle. When Glc level decreases, $\beta \mathrm{MeG}$ again displaces it to occupy the binding site and the cycle repeats. The circled numbers $1-4$ indicate the reaction sequence of the cycle (as modified from Fig. 1S). Cells and their parts are not drawn to scale; the molecular model of lectin is based on ConA; and the structure and cofactors were generated using coordinates from the Protein Data Bank (PDB) entries 1LES and 5CNA (Naismith et al. 1994, Casset et al. 1995).

carbon reactions of photosynthesis, due to a bypass of the lectin cycle. The bypass begins within minutes after the active ingredient, $\alpha \mathrm{MeM}$, has entered the cells. It binds the carbon reaction lectins tightly and displaces sugars, represented by Glc. While the binding sites of these lectins are occupied by $\alpha \mathrm{MeM}$, fresh Glc generated from the photosynthetic carbon reduction cycle is locked out by the high-affinity ligand, bypassing the lectins. Fresh Glc molecules, which continue to bypass the lectins for weeks after treatment, are directed to growth and respiration and may be translocated further to plant tissues in roots and shoots, including, stems, foliage, flowers, fruits, and seeds. The induced lectin bypass in plant cells is shown in Fig. 3 (as modified from Fig. 1S; an animation of the bypass is shown in Fig. 2S, supplement).

\section{Glycoregulation}

Modulation of glycoregulation has been confirmed in the field after treatments with the first commercial formulation which included the active ingredient $\alpha \mathrm{MeM}$. For example, treated field-grown melons and grapes showed significant increases in soluble sugar content as compared to the controls (Nonomura et al. 2018a,b). Notably, during daylight hours, sugars allocated to roots or symbionts may yield the products of respiratory metabolism, water, and $\mathrm{CO}_{2}$. Those end products, after upward transport from roots to shoots, may favor photosynthesis, particularly with elevated $\mathrm{CO}_{2}$ in the chloroplast (for an example of transport from roots to shoots in trees, see Bloemen et al. 2013; for symbionts see ten Veldhuis et al. 2020).

\section{Concluding remarks}

\section{An abundance of lectins}

Lectins are proteins with a history that can be traced to the naming of plant agglutinins by William C. Boyd in 1954. As suggested by their Latin name roots, 'legere' (meaning, to pick or select), lectins bind carbohydrates according to varying specificities and affinities. The ranking of lectins as some of the most important proteins in photosynthetic protists and plants is based on the view that they are translators of the glycocode (Nilsson 2007) and the abundance of their presence in photosynthetic organisms may rank second only to that of Rubisco. Indeed, experiments by Benson et al. (2009) and genetic studies by Van Holle and Van Damme (2019) point to genomic evolution by the expansion of lectin families from algae to vascular plants. The key point in understanding the function of lectins, in the carbon reactions, is the reversibility of its carbohydrate-binding property and the ability of different sugars to simultaneously compete for and displace already bound ligands based on their available concentrations and affinities (Sharon and Lis 2007). The occupants of CRDs are, therefore, displaceable by chemical competitors. 


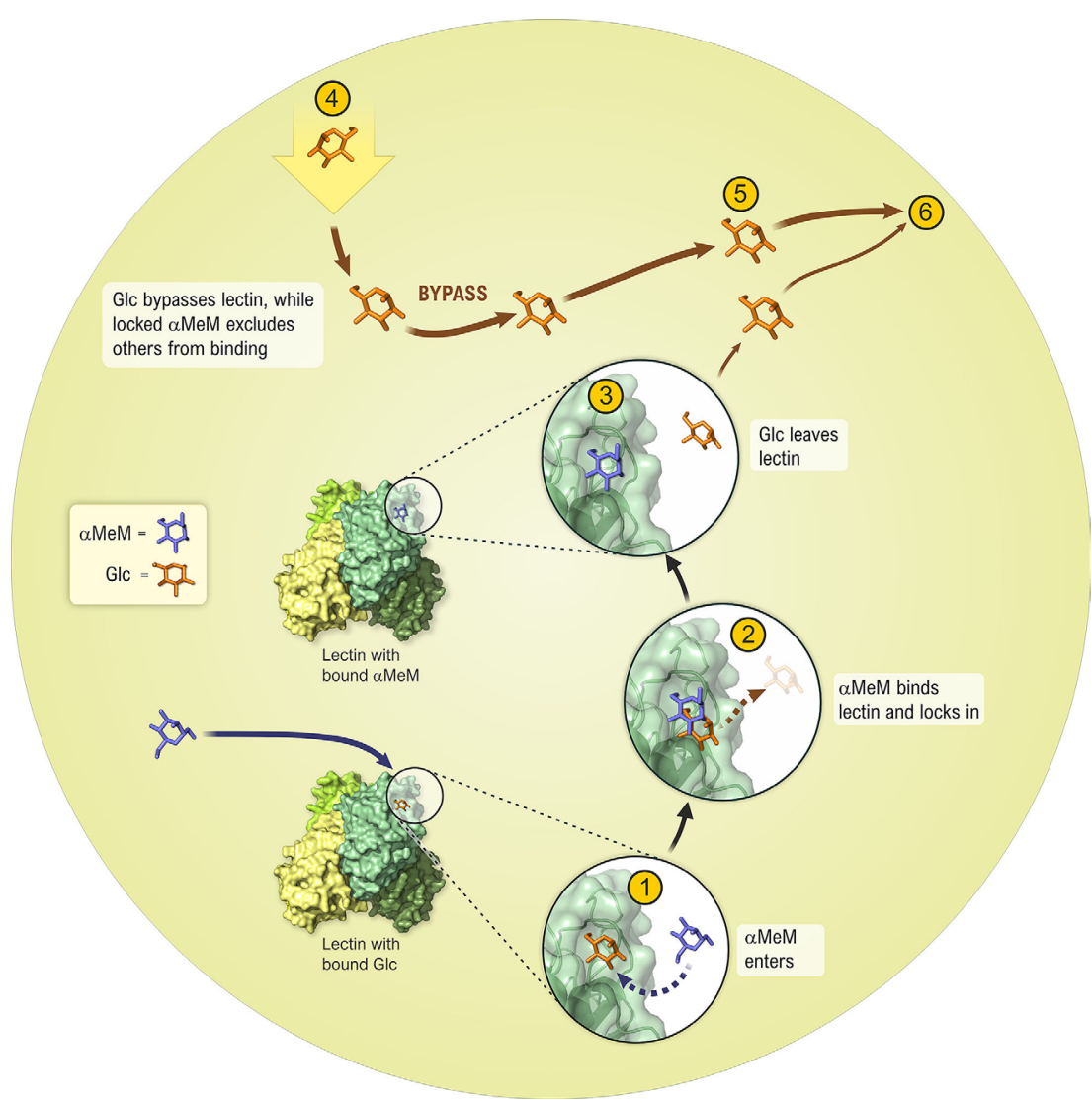

Fig. 3. Diagram of the lectin bypass in plants. Exogenous methyl- $\alpha$-D-mannopyranoside $(\alpha \mathrm{MeM})$ induces the bypass. After $\alpha \mathrm{MeM}$ is in the vacuole of plant cells (1), it binds carbon reaction lectins (2) and displaces Glc (3). While $\alpha \mathrm{MeM}$ is bound tightly and locked, fresh Glc from the photosynthetic carbon reduction cycle (4) cannot bind lectins. Instead, Glc bypasses lectins (5). This leads to growth (6). The circled numbers 1-6 indicate the reaction sequences (as modified from Fig. 1S). Sugar products are represented by Glc; cell parts are not drawn to scale; the molecular model of lectin is based on ConA; and the structure and cofactors were generated using coordinates from the PDB entries 1LES and 5CNA (Naismith et al. 1994, Casset et al. 1995).

\section{The vacuole as the hub of glycoregulation}

Vacuoles are the largest organelles, often occupying greater than three quarters of the volume inside the plant cell, and we recognize that they are the cellular location for the storage of metabolic products, including sugars and proteins, as nutrients (Zhang et al. 2015). Given the abundance of vacuolar lectins, we point out that they may be essential for the role that the vacuole plays in maintaining turgor, exchange and storage of metabolites, detoxification, as well as homeostasis (Marty 1999).

When sugars are bound to lectins, they are osmotically inert, but free sugars may be active. Accumulation of free glucose in the vacuole may account for the osmotic potential required for the maintenance of turgor, pressing the tonoplast against the cell wall and driving cell expansion (Aluri and Büttner 2007). Such stiffening of plant cells (shown in an animation in Fig. 3S, supplement) may have contributed to the recovery from midday wilt that had been observed in crops (Nonomura and Benson 1992a, Nonomura et al. 2018a). Thus, the role of lectins in the modulation of glycoregulation, by controlling the concentrations of available free sugars, is important for the physical and metabolic functions that are essential for the life of the plant. As explained in this minireview, the role of lectins in the carbon reactions of photosynthesis is equally critical for the physical and metabolic well-being of the plant. For crops, vacuolar processes may contribute to the flavor of fruits and vegetables. Moreover, by enhancement of the turgor pressure in flowers, leafy greens, and fruits, the treated end product may be crisp and deeply flavorful while also lengthening shelf life.

\section{The plant growth regulator, $\alpha \mathrm{MeM}$}

Besides CRDs, many plant lectins also possess specific independent binding sites for hydrophobic ligands (Komath et al. 2006). Early studies by Roberts and Goldstein (1983) showed that such binding sites in lectins from Phaseolus lunatus (lima bean), P. vulgaris (kidney bean), Glycine max (soybean), and Dolichos biflorus (horse gram) could bind to plant growth regulators such as $\mathrm{N}^{6}$-benzyladenine, kinetin, zeatin, and zeatin riboside. Besides, Edelman and Wang (1978) showed that ConA from Canavalia ensiformis (jack bean) binds the auxin, indoleacetic acid (IAA). Further, Benson et al. (2009) observed growth enhancement of canola when the phytohormones, IAA and kinetin, were formulated with $\mathrm{MeG}$; and Nonomura et al. (2011) showed the efficacy of sugar-conjugated plant growth regulators in modulating plant growth.

Thus, lectins may be regarded as the central mediators of information transfer not only due to their ability to translate the glycocode via their interactions with specific monosaccharides as well as the terminal ligands of oligosaccharides, glycoproteins, and glycolipids (Nilsson 2007) but also by their interactions with plant growth regulators. Recently lectins have been subsumed under the larger group of carbohydrate-binding agents (CBAs), 
which include both proteinaceous and nonproteinaceous agents as well as synthetic molecules that can specifically bind carbohydrates. However, as we note here, the definition of lectins as CBAs limits our understanding of the role of lectins within plants.

The plant growth regulator $\alpha \mathrm{MeM}$, discussed in this minireview, alters the metabolic pathways of displaced compounds and fresh photosynthates from the photosynthetic carbon reduction cycle by blocking their access to their endogenous receptors on the carbon reaction lectins within the vacuoles. Enhanced flower counts, vibrant colors from sugar-based pigments such as anthocyanins, and improved yields have been observed after field treatments with the plant growth regulator formulation (Nonomura et al. 2018a,b). In addition to glycoregulation, we shall investigate its effect on other networks (see, for example, Law et al. 2020); furthermore, related metabolic fluxes in the carbon reactions of guard cells may lead to investigations of stomatal movement (see, for example, Zhang et al. 2018).

\section{Growth, productivity and more}

We have focused here on carbon reactions in the vacuoles, and yet, these pathways diverge widely from points of growth that incorporate carbon backbones into the synthesis of amino acids by the different pathways of nitrogen assimilation and photorespiration (Bloom 2015). The reduction of nitrate to ammonia $\left(\mathrm{NH}_{3}\right)$, the incorporation of $\mathrm{NH}_{3}$ into amino acids, and the carbon reduction cycle operate in the chloroplast; and it is noteworthy that carbon and nitrogen assimilation are integrated processes (Bloom 2015, Thompson et al. 2017). Bloom et al. (2002) showed that co-application of elevated $\mathrm{CO}_{2}$ with nitrogen fertilizers, particularly with the input of $\mathrm{NH}_{3}$, promoted the synthesis of nitrogenous end-products. These observations led Benson et al. (2009) to begin experimenting with nitrogen supplementation of exogenous lectin ligands. In consideration of the correlation of photosynthetic capacity to nitrogen content (see, for example, Hymus et al. 2001, Jin et al. 2015), and the implications for drought relief in crops under elevated $\mathrm{CO}_{2}$, by photosynthetic and nitrogenuse efficiency (Sekhar et al. 2020), applications of nitrogenous plant nutrition in conjunction with modulation of glycoregulation may benefit vegetative productivity in the field, particularly in the crops of leafy greens.

Historically, Hoagland and Arnon (1950) must be acknowledged for defining the essential nutrient elements required for the growth of plants. We add that plant growth regulators are known to interact with these nutrients. For example, phytohormones are involved in the regulation of nitrogen uptake systems, particularly with regard to lateral root development in response to changes in nitrogen availability (Kiba et al. 2011). Thus, as primary, secondary and micronutrients are co-applied with $\alpha \mathrm{MeM}$ to various crops, adjustments may be made to the seasonal programs to meet quality standards and marketable quantities of harvests (see, e.g., Fageria et al. 2008, 2009; Pier and Barlow 2018).

In contrast to other plant growth regulators, $\alpha \mathrm{MeM}$ modulates glycoregulation. We know that two plant nutrients, $\mathrm{Ca}^{2+}$ and $\mathrm{Mn}^{2+}$, are also integral to carbohydrate binding by many Glc/Man specific lectins (Naismith et al. 1994, Loris et al. 1998). Nonomura and Benson (2014) found these specific cations to be a prerequisite for plant growth response to exogenous ligands. Therefore, we suggest that these elements also form the basis for recognition of the high binding specificity for locked ligands (in this case, $\alpha \mathrm{MeM}$ ) in the carbon reaction lectins, making them essential for the transfer of this technology to agriculture.

To sum up, in this overview we have presented the discoveries and innovations that led to the elucidation of the plant lectin cycle and its bypass. We have described here how the scientific investigations have progressed from molecular (carbohydrate, protein), to cellular (chloroplast, vacuole), and to organismal (whole plant) levels. Finally, as we begin to comprehend the relationship of the structure and function of lectins to the advancement of photosynthetic efficiency, transfer to agriculture is our goal and hope of our international interdisciplinary collaborations (Biel and Fomina 2015, Nonomura et al. 2017, 2018a,b; Govindjee et al. 2020).

\section{Label information}

The natural product $\alpha \mathrm{MeM}$ is registered by the United States Environmental Protection Agency (EPA) under the brand name, BRANDT GlucoPro, and the master label, iH026a (Nonomura et al. 2018b). This label is approved for foliar spray, drench, and chemical irrigation application; use on listed crops grown in fields, orchards, vineyards, greenhouses, and nurseries; use on ornamentals, flowers, lawns, commercial turf, recreational areas, and golf courses; and for use on field-grown, greenhouse-grown, nursery-grown, and hydroponically-grown ornamentals and florals. This proven plant growth regulator: increases yields, improves crop quality, enhances crop turgidity, diminishes midday wilt, promotes shoot and root growth, promotes greater root mass development, improves seed vigor, increases sweetness in fruits, increases blossoms, diminishes sun scorch, reduces the incidence of blossom end rot, enlarges foliage, encourages fuller plants, and improves stress tolerance. For general instructions on-field use of the first commercial product featuring $\alpha \mathrm{MeM}$, the GlucoPro brochure is available at URL: https://brandt.co/media/11012/brandt-glucopro-brochure. pdf. For U.S. Patents BRANDT iHammer proprietary technologies, see Brandt.Co/iHammerPatents1/, Brandt. Co/iHammerPatents2/.

\section{References}

Aleksidze G. Ya., Litvinov A.I., Vyskrebentseva E.I.: The model of Calvin cycle enzyme organization on thylakoid membranes with the involvement of the Photosystem I lectin. - Russ. J. Plant Physl+ 49: 137-141, 2002.

Aluri S., Büttner M.: Identification and functional expression of the Arabidopsis thaliana vacuolar glucose transporter 1 and its role in seed germination and flowering. - P. Natl. Acad. Sci. USA 104: 2537-2542, 2007. 
Armbruster U., Strand D.D.: Regulation of chloroplast primary metabolism. - Photosynth. Res. 145: 1-3, 2020.

Aubert S., Choler P., Pratt J. et al:: Methyl- $\beta$-D-glucopyranoside in higher plants: Accumulation and intracellular localization in Geum montanum L. leaves and in model systems studied by ${ }^{13} \mathrm{C}$ nuclear magnetic resonance. - J. Exp. Bot. 55: 21792189, 2004.

Barre A., Bourne Y., Van Damme E.J.M. et al.: Mannose-binding plant lectins: different structural scaffolds for a common sugar-recognition process. - Biochimie 83: 645-651, 2001.

Barre A., Bourne Y., Van Damme E.J.M., Rougé P.: Overview of the structure-function relationships of mannose-specific lectins from plants, algae and fungi. - Int. J. Mol. Sci. 20: 254, 2019.

Bassham J.A.: Mapping the carbon reduction cycle: a personal retrospective. - Photosynth. Res. 76: 35-52, 2003.

Benson A.A.: Following the path of carbon in photosynthesis: a personal story. - Photosynth. Res. 73: 29-49, 2002.

Benson A.A., Nonomura A.M.: The path of carbon in photosynthesis: methanol inhibition of glycolic acid accumulation. In: Murata N. (ed.): Research in Photosynthesis, Proceedings of the IX International Congress on Photosynthesis. P-522. Kluwer, Dordrecht 1992.

Benson A.A., Nonomura A.M., Gerard V.A.: The path of carbon in photosynthesis. XXV. Plant and algal growth responses to glycopyranosides. - J. Plant Nutr. 32: 1185-1200, 2009.

Biel K.Y., Fomina I.R.: Benson-Bassham-Calvin cycle contribution to the organic life on our planet. - Photosynthetica 53: 161-167, 2015

Biel K.Y., Nonomura A.M., Benson A.A., Nishio J.N.: The path of carbon in photosynthesis. XXVI. Uptake and transport of methylglucopyranoside throughout plants. - J. Plant Nutr. 33: 902-913, 2010.

Bloemen J., McGuire M.A., Aubrey D.P. et al.: Transport of rootrespired $\mathrm{CO}_{2}$ via the transpiration stream affects aboveground carbon assimilation and $\mathrm{CO}_{2}$ efflux in trees. - New Phytol. 197: 555-565, 2013.

Bloom A.J.: Photorespiration and nitrate assimilation: a major intersection between plant carbon and nitrogen. - Photosynth. Res. 123: 117-128, 2015.

Bloom A.J., Smart D.R., Nguyen D.T., Searles P.S.: Nitrogen assimilation and growth of wheat under elevated carbon dioxide. - P. Natl. Acad. Sci. USA 99: 1730-1735, 2002.

Buchanan B.B.: The carbon (formerly dark) reactions of photosynthesis. - Photosynth. Res. 128: 215-217, 2016.

Calvin M., Benson A.A.: The path of carbon in photosynthesis. Science 107: 476-480, 1948.

Casset F., Hamelryck T., Loris R. et al.: NMR, molecular modeling, and crystallographic studies of lentil lectin-sucrose interaction. - J. Biol. Chem. 270: 25619-25628, 1995.

Dam T.K., Brewer C.F.: Fundamentals of lectin-carbohydrate interactions. - In: Kamerling J.P., Boons G.J., Lee Y.C. et al. (ed.): Comprehensive Glycoscience. Pp. 397-452. Elsevier, Oxford 2007

Edelman G.M., Wang J.L.: Binding and functional properties of concanavalin A and its derivatives. III. Interactions with indoleacetic acid and other hydrophobic ligands. - J. Biol. Chem. 253: 3016-3022, 1978.

Fageria N.K., Baligar V.C., Li Y.C.: The role of nutrient efficient plants in improving crop yields in the twenty first century. J. Plant Nutr. 31: 1121-1157, 2008.

Fageria N.K., Barbosa Filho M.P., Moreira A., Guimarães C.M.: Foliar fertilization of crop plants. - J. Plant Nutr. 32: 10441064, 2009.

Fomina I.R., Biel K.Y.: Photosynthetic carbon metabolism: strategy of adaptation over evolutionary history. - In:
Allakhverdiev S.I. (ed.): Photosynthesis: New Approaches to the Molecular, Cellular, and Organismal Levels. Pp. 233-326. Scrivener Publishing, Austin 2016.

Gout E., Aubert S., Bligny R. et al.: Metabolism of methanol in plant cells. Carbon-13 nuclear magnetic resonance studies. Plant Physiol. 123: 287-296, 2000.

Govindjee G., Nonomura A., Lichtenthaler H.K.: Remembering Melvin Calvin (1911-1997), a highly versatile scientist of the 20th century. - Photosynth. Res. 143: 1-11, 2020.

Hincha D.K., Bakaltcheva I., Schmitt J.M.: Galactose-specific lectins protect isolated thylakoids against freeze-thaw damage. - Plant Physiol. 103: 59-65, 1993.

Hoagland D.R., Arnon D.I.: The water-culture method for growing plants without soil. California Agricultural Experiment Station Circular 347. The College of Agriculture, University of California, Berkeley 1950.

Hymus G.J., Baker N.R., Long S.P.: Growth in elevated $\mathrm{CO}_{2}$ can both increase and decrease photochemistry and photoinhibition of photosynthesis in a predictable manner. Dactylis glomerata grown in two levels of nitrogen nutrition. Plant Physiol. 127: 1204-1211, 2001.

Jin X., Yang G., Tan C., Zhao C.: Effects of nitrogen stress on the photosynthetic $\mathrm{CO}_{2}$ assimilation, chlorophyll fluorescence, and sugar-nitrogen ratio in corn. - Sci. Rep.-UK 5: 9311, 2015.

Kiba T., Kudo T., Kojima M., Sakakibara H.: Hormonal control of nitrogen acquisition: roles of auxin, abscisic acid, and cytokinin. - J. Exp. Bot. 62: 1399-1409, 2011.

Komath S.S., Kavitha M., Swamy M.J.: Beyond carbohydrate binding: new directions in plant lectin research. - Org. Biomol. Chem. 4: 973-988, 2006.

Kovalchuk N.V., Melnykova N.M., Musatenko L.: Role of phytolectin in the life cycle of plants. - Biopolym. Cell 28: 171-180, 2012.

Lambin J., Asci S.D., Dubiel M. et al.: OsEUL lectin gene expression in rice: stress regulation, subcellular localization and tissue specificity. - Front. Plant Sci. 11: 185, 2020.

Lannoo N., Van Damme E.J.M.: Nucleocytoplasmic plant lectins. - BBA-Gen. Subjects 1800: 190-201, 2010.

Lannoo N., Van Damme E.J.M.: Lectin domains at the frontiers of plant defense. - Front. Plant Sci. 5: 397, 2014.

Laus M.C., Logman T.J., Lamers G.E. et al:: A novel polar surface polysaccharide from Rhizobium leguminosarum binds host plant lectin. - Mol. Microbiol. 59: 1704-1713, 2006.

Law S.R., Kellgren T., Björk R. et al.: Centralization within sub-experiments enhances the biological relevance of gene co-expression networks: a plant mitochondrial case study. Front. Plant Sci. 11: 524, 2020.

Loris R., Hamelryck T., Bouckaert J., Wyns L.: Legume lectin structure. - BBA-Protein Struct. Mol. Enzymol. 1383: 9-36, 1998.

Marty F.: Plant Vacuoles. - Plant Cell 11: 587-599, 1999.

Naismith J.H., Emmerich C., Habash J. et al.: Refined structure of concanavalin A complexed with methyl $\alpha$-Dmannopyranoside at $2.0 \AA$ resolution and comparison with the saccharide-free structure. - Acta Crystallogr. D 50: 847$858,1994$.

Naismith J.H., Field R.A.: Structural basis of trimannoside recognition by concanavalin A. - J. Biol. Chem. 271: 972976, 1996.

Nilsson C.L.: Lectins: Analytical Technologies. Pp. 442. Elsevier, Amsterdam 2007.

Nonomura A.M., Benson A.A.: The path of carbon in photosynthesis. XXIV. Improved crop yields with methanol. - P. Natl. Acad. Sci. USA 89: 9794-9798, 1992a.

Nonomura A.M., Benson A.A.: The path of carbon in photosyn- 
thesis. Methanol and light. - In: Murata N. (ed.): Research in Photosynthesis, Proceedings of the IX International Congress on Photosynthesis. P-589. Kluwer, Dordrecht 1992b.

Nonomura A.M., Benson A.A.: The path of carbon in photosynthesis. XXIX. Glass microbeads. - J. Plant Nutr. 35: 18961909, 2012.

Nonomura A.M., Benson A.A.: The path of carbon in photosynthesis. XXX. $\alpha$-Mannosides. - In: Dubinsky Z. (ed.): Photosynthesis. Pp. 3-22. InTech, Rijeka 2013.

Nonomura A.M., Benson A.A.: The path of carbon in photosynthesis. XXXI. The role of lectins. - J. Plant Nutr. 37: 785-794, 2014.

Nonomura A.M., Benson A.A., Biel K.Y.: The path of carbon in photosynthesis. XXVII. Sugar-conjugated plant growth regulators enhance general productivity. - J. Plant Nutr. 34: 653-664, 2011.

Nonomura A.M., Biel K.Y., Fomina I.R. et al.: Benson's protocol.In: Fomina I.R., Biel K.Y., Soukhovolsk V.G. (ed.): Complex Biological Systems: Adaptation and Tolerance to Extreme Environments. $2^{\text {nd }}$ Edition, extended. Pp. 463-508. John Wiley \& Sons, Inc., Hoboken 2018a. doi: 10.1002/9781119510390. ch11.

Nonomura A.M., Cullen B.A., Benson A.A.: The path of carbon in photosynthesis. XXVIII. Responses of plants to polyalkylglycopyranose and polyacylglycopyranose. - In: Najafpour M.M. (ed.): Advances in Photosynthesis: Fundamental Aspects. Pp. 259-271. InTech, Rijeka 2012.

Nonomura A.M., Holtz B., Biel K.Y. et al.: The paths of Andrew A. Benson: a radio-autobiography. - Photosynth. Res. 134: 93-105, 2017.

Nonomura A.M., Pedersen A., Brummel D.P. et al.: Brandt iH026a plant growth regulator. - Photosynthetica 56: 411417, 2018b.

Nonomura A.M., Shevela D., Komath S.S. et al.: A plant growth regulator for photosynthesis. Govindjee's Educational Poster Series, 2020. doi: 10.13140/RG.2.2.30634.44480.

Pier J., Barlow D. (ed.): Western Fertilizer Handbook. $3^{\text {rd }}$ Edition. Western Plant Health Association. Pp. 400. Waveland Press, Long Grove 2018. ISBN: 1-4786-3846-x.

Roberts D.D., Goldstein I.J.: Adenine binding sites of the lectin from lima beans (Phaseolus lunatus). - J. Biol. Chem. 258: 13820-13824, 1983.

Schröder W.P., Petit P.X.: Flow cytometry of spinach chloroplasts. - Plant Physiol. 100: 1092-1102, 1992.

Schwarz F.P., Puri K.D., Bhat R.G., Surolia A.: Thermodynamics of monosaccharide binding to concanavalin A, pea (Pisum sativum) lectin, and lentil (Lens culinaris) lectin. - J. Biol.
Chem. 268: 7668-7677, 1993.

Sekhar K.M., Kota V.R., Reddy T.P. et al.: Amelioration of plant responses to drought under elevated $\mathrm{CO}_{2}$ by rejuvenating photosynthesis and nitrogen use efficiency: implications for future climate-resilient crops. - Photosynth. Res., 2020. doi: $10.1007 / \mathrm{s} 11120-020-00772-5$.

Sharkey T.D.: Discovery of the canonical Calvin-Benson cycle. Photosynth. Res. 140: 235-252, 2019.

Sharon N., Lis H.: Lectins. $2^{\text {nd }}$ Edition. Pp. 454. Springer, Dordrecht 2007.

Shevela D., Björn L.O., Govindjee G.: Photosynthesis: Solar Energy for Life. Pp. 204. World Scientific Publishing, Singapore 2018. doi: 10.1142/10522.

Shevela D., Do H.-N., Fantuzzi A. et al.: Bicarbonate-mediated $\mathrm{CO}_{2}$ formation on both sides of Photosystem II. - Biochemistry 59: 2442-2449, 2020.

Shevela D., Eaton-Rye J.J., Shen J.R., Govindjee: Photosystem II and unique role of bicarbonate: a historical perspective. BBA-Bioenergetics 1817: 1134-1151, 2012.

Smeets K., Van Damme E.J.M., Verhaert P. et al.: Isolation, characterization and molecular cloning of the mannosebinding lectins from leaves and roots of garlic (Allium sativum L.). - Plant Mol. Biol. 33: 223-234, 1997.

ten Veldhuis M.C., Ananyev G., Dismukes G.C.: Symbiosis extended: exchange of photosynthetic $\mathrm{O}_{2}$ and fungal-respired $\mathrm{CO}_{2}$ mutually power metabolism of lichen symbionts. Photosynth. Res. 143: 287-299, 2020.

Thompson M., Gamage D., Hirotsu N. et al.: Effects of elevated carbon dioxide on photosynthesis and carbon partitioning: a perspective on root sugar sensing and hormonal crosstalk. Front. Physiol. 8: 578, 2017.

Van Damme E.J.M., Lannoo N., Peumans W.: Plant lectins. Adv. Bot. Res. 48: 107-209, 2008.

Van Damme E.J.M., Peumans W.J., Pusztai A., Bardocz S.: Handbook of Plant Lectins: Properties and Biomedical Applications. Pp. 466. John Wiley \& Sons, New York 1998. ISBN: 978-0-471-96445-2.

Van Holle S., Van Damme E.J.M.: Messages from the past: new insights in plant lectin evolution. - Front. Plant Sci. 10: 36, 2019.

Zhang C., Hicks G.R., Raikhel N.V.: Molecular composition of plant vacuoles: important but less understood regulations and roles of tonoplast lipids. - Plants-Basel 4: 320-333, 2015.

Zhang J., Wang N., Miao Y. et al.: Identification of SLAC1 anion channel residues required for $\mathrm{CO}_{2} /$ bicarbonate sensing and regulation of stomatal movements. - P. Natl. Acad. Sci. USA 115: 11129-11137, 2018.

(C) The authors. This is an open access article distributed under the terms of the Creative Commons BY-NC-ND Licence. 